This item was submitted to Loughborough's Research Repository by the author.

Items in Figshare are protected by copyright, with all rights reserved, unless otherwise indicated.

\title{
A comparison of the benzylic and the allylic group as a donor in the formal [4+2] cycloaddition to tetrahydropyrans using donor-acceptor cyclobutanes
}

PLEASE CITE THE PUBLISHED VERSION

http://dx.doi.org/10.1016/j.tetlet.2017.06.046

\section{PUBLISHER}

(C) Elsevier Ltd.

VERSION

AM (Accepted Manuscript)

\section{PUBLISHER STATEMENT}

This work is made available according to the conditions of the Creative Commons Attribution-NonCommercialNoDerivatives 4.0 International (CC BY-NC-ND 4.0) licence. Full details of this licence are available at: https://creativecommons.org/licenses/by-nc-nd/4.0/

\section{LICENCE}

CC BY-NC-ND 4.0

\section{REPOSITORY RECORD}

Ahmed, Awais, Steven D.R. Christie, and Gareth J. Pritchard. 2019. "A Comparison of the Benzylic and the Allylic Group as a Donor in the Formal [4+2] Cycloaddition to Tetrahydropyrans Using Donor-acceptor Cyclobutanes". figshare. https://hdl.handle.net/2134/25895. 


\section{Accepted Manuscript}

A Comparison of the Benzylic and the Allylic Group as a Donor in the Formal [4+2] Cycloaddition to Tetrahydropyrans using Donor-Acceptor Cyclobutanes

Awais Ahmed, Steven D.R. Christie, Gareth J. Pritchard

PII:

$$
\text { S0040-4039(17)30777-3 }
$$

DOI: http://dx.doi.org/10.1016/j.tetlet.2017.06.046

Reference: TETL 49038

To appear in:

Tetrahedron Letters

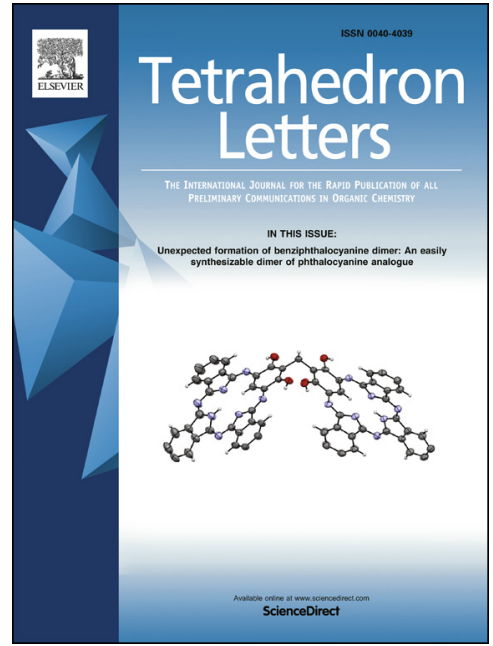

Received Date: $\quad 12$ April 2017

Revised Date: $\quad 6$ June 2017

Accepted Date: $\quad$ 14 June 2017

Please cite this article as: Ahmed, A., Christie, S.D.R., Pritchard, G.J., A Comparison of the Benzylic and the Allylic Group as a Donor in the Formal [4+2] Cycloaddition to Tetrahydropyrans using Donor-Acceptor Cyclobutanes, Tetrahedron Letters (2017), doi: http://dx.doi.org/10.1016/j.tetlet.2017.06.046

This is a PDF file of an unedited manuscript that has been accepted for publication. As a service to our customers we are providing this early version of the manuscript. The manuscript will undergo copyediting, typesetting, and review of the resulting proof before it is published in its final form. Please note that during the production process errors may be discovered which could affect the content, and all legal disclaimers that apply to the journal pertain. 


\section{Graphical Abstract}

To create your abstract, type over the instructions in the template box below.

Fonts or abstract dimensions should not be changed or altered.

\section{A Comparison of the Benzylic and the Allylic group as a Donor in the Formal [4+2] \\ Cycloaddition to Tetrahydropyrans using Donor-Acceptor Cyclobutanes.}

Awais Ahmed, Steven D. R. Christie* and Gareth J. Pritchard*
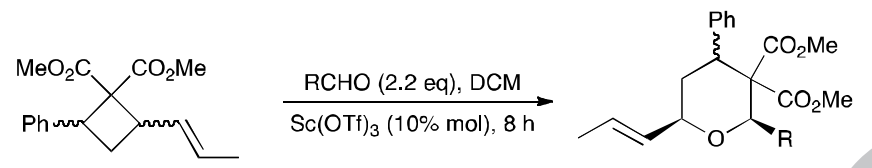


\title{
A Comparison of the Benzylic and the Allylic Group as a Donor in the Formal [4+2] Cycloaddition to Tetrahydropyrans using Donor-Acceptor Cyclobutanes
}

\author{
Awais Ahmed, Steven D. R. Christie* and Gareth J. Pritchard* \\ Department of Chemistry, University of Loughborough, Loughborough, Leicestershire, LE11 3TU, UK.
}

ARTICLE INFO

\section{ABSTRACT}

The allyl group was shown to be preferred over the benzyl group as a donor in the formal $[4+2]$-cycloaddition reaction between a donor-acceptor cyclobutane and various aldehydes to give tetrahydropyrans.

Received

Received in revised form

Accepted

Available online

Keywords:

Cyclobutanes

Tetrahydropyrans

Cycloaddition

Lewis Acids

\section{Introduction}

Heterocyclic motifs play a key role in organic chemistry, embracing pharmaceutical drugs, natural products and material chemistry. The development of new routes towards heterocyclic compounds is a key challenge for synthetic chemists. We have added to this field a number of methodologies, including stoichiometric organometallic; ${ }^{1,2}$ palladium mediated reactions; ${ }^{3}$ biomimetic methods $;^{4}$ condensation of reactive electrophilic systems, ${ }^{5}$ and Lewis acid mediated reactions. ${ }^{6}$ As part of our studies, we have previously reported the formal [4+2]-cycloaddition reaction between donor-acceptor cyclobutanes and aldehydes to give tetrahydropyrans, under Lewis acid conditions (Scheme 1). ${ }^{2}$

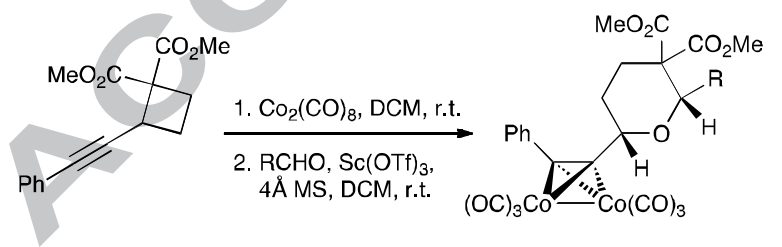

Scheme 1. Formal [4+2]-cycloaddition reaction between donor-acceptor cyclobutane and aldehydes.

The use of donor-acceptor cyclobutanes in synthesis has expanded since its initial report. ${ }^{7}$ Of note amongst those reports are: Johnson and co-workers simultaneous report of chemistry

\footnotetext{
* Corresponding authors.

E-mail addresses: G.J.Pritchard@lboro.ac.uk (G. J. Pritchard), S.D.Christie@lboro.ac.uk (S. D. R. Christie).
}

closely related to ours; ${ }^{8}$ the use of an oxygen atom as the donor has been established by Pagenkopf and others; ${ }^{9}$ the use of cyclobutanones as shown by Matsuo $;{ }^{10}$ and the construction of heteroaromatic systems using cyclobutanes as reported by Rao. ${ }^{11}$

Herein, we report a recent study where we have added extra complexity to the donor-acceptor cyclobutane $[4+2]$-cycloaddition reaction. Johnson and co-workers have previously shown that both an aromatic or allylic group can act as the donor in the cyclobutane starting material, ${ }^{8}$ but there was no discussion as to which was preferred. We have therefore devised an experiment to compare the reactivity of these donor groups. If there are two donor groups on the cyclobutane, one phenyl and one allyl group, it would be interesting to observe which bond will cleave to allow the formal $[4+2]$-cycloaddition to occur under Lewis acid conditions (Scheme 2). This would provide more insight into the mechanism of the $[4+2]$-cycloaddition reaction, as well as the introduction of extra substitution to the tetrahydropyran product, resulting in new compounds difficult to access by other means.

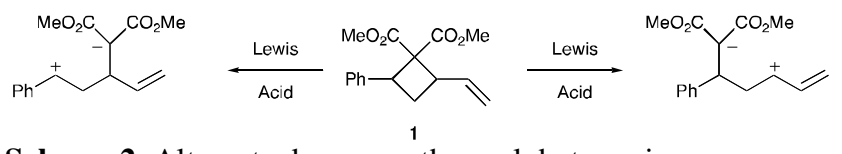

Scheme 2. Alternate donors on the cyclobutane ring.

\section{Results and Discussion}

We based our route to compound $\mathbf{1}$ on the elegant chemistry developed by Boeckman and co-workers, who used an anionic rino slocure reastion to nrenare enantiomerically nure 
vinylcyclobutane derivatives. ${ }^{12}$ Staring with the Michael addition reaction between dimethyl malonate and cinnamaldehyde under the reaction conditions developed by Ma and co-workers, ${ }^{13}$ the Michael product 2 was formed in $45 \%$ yield. We did not attempt to optimize the reaction or control the enantioselectivity of the reaction at this stage. Subsequent Wittig reaction with acetylmethylene triphenylphosphorane gave ketone $\mathbf{3}$ in $70 \%$ yield. Following the steps developed by Boeckman and co-workers, Luche reduction of the ketone and conversion into the phenyl carbonate gave an inseparable mixture of diastereoisomers (1:1). Cyclisation to the required cyclobutane 4 was carried out using sodium hydride in toluene at $50{ }^{\circ} \mathrm{C}$. An inseparable 3:1 mixture of diastereoisomers was isolated in $88 \%$ yield. Replacing the leaving group with methyl carbonate did not change the ratio of the diastereoisomers but also lowered the yield. The change in the diastereomeric ratio suggests that one isomer is more readily able to cyclise.

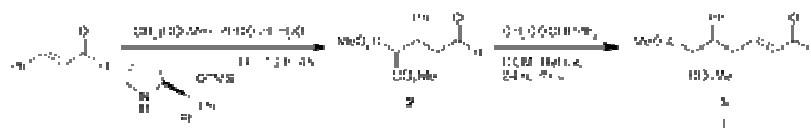

$$
\begin{aligned}
& \text { - = }
\end{aligned}
$$

Scheme 3. Synthetic route to donor-acceptor cyclobutane 4.

With a suitably substituted cyclobutane $\mathbf{4}$ in hand, we were able to carry out the key formal [4+2]-cycloaddition. Using previously developed reaction conditions, cyclobutane $\mathbf{4}$ was treated with varying equivalents of benzaldehyde in the presence of $\mathrm{Sc}(\mathrm{OTf})_{3}(10 \mathrm{~mol} \%)$ in DCM. Gratifyingly the desired formal $[4+2]$-cycloaddition tetrahydropyran product was obtained along with various by-products, which were all isolated and identified (Scheme 4, Table 1). It was immediately apparent that cyclobutane 4 was less reactive than analogous literature compounds, since larger equivalents of the aldehyde was required to achieve workable yields. This could possibly be explained by the increased steric demand of the cyclobutane starting material which is known to hinder cycloaddition reactions.

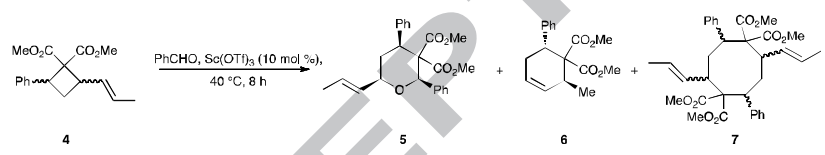

Scheme 4. Initial attempt of formal [4+2]-cycloaddition reaction using cyclobutane 4.

Table 1. Comparison of different amounts of benzaldehyde.

\begin{tabular}{|c|c|c|c|}
\hline PhCHO (equiv.) & Yield 5(\%) & Yield 6(\%) & Yield 7 (\%) \\
\hline 1.2 & 18 & 20 & 0 \\
\hline 2.2 & 18 & 25 & 2 \\
\hline 5.0 & 47 & 17 & 0 \\
\hline
\end{tabular}

The target pyran product $\mathbf{5}$ was purified and spectroscopic analysis, including nOe experiments, showed it to be the single diastereoisomer $\mathbf{5}$, arising from breaking of the cyclobutane bond that would give rise to an allyl cation. The best yield (47\%) was obtained when a large excess of aldehyde (5 equiv.) was used. We did not observe, or isolate, any tetrahydropyran products that would arise from ring opening to give the benzyl cation. The major by-product of the reaction was the rearranged cyclohexene product 6, the stereochemistry of this product was also established by nOe experiments. A small amount of dimer 7 was also isolated from the complex reaction mixture on one occasion.
We were able to determine the regiochemistry of the dimer product but not its stereochemistry. Both the cyclohexene $\mathbf{6}$ and dimer $\mathbf{7}$ are also the result of the bond cleavage that leads to the allyl cation, in accordance to the formation of tetrahydropyran $\mathbf{5}$.

We next tried to optimize the reaction conditions in order to improve the ratio of the target tetrahydropyran product to side-products by experimenting with different solvents and catalysts (Table 2). Despite our best efforts, the initial reaction conditions appeared to be best suited to this formal $[4+2]$-cycloaddition reaction. Changing the solvent had a detrimental effect on the reaction outcome and other Lewis acids did not provide any advantage over $\mathrm{Sc}(\mathrm{OTf})_{3}$, similar to the findings of Johnson and co-workers. ${ }^{8}$

Table 2. Variations of solvent and Lewis acid catalyst used in cycloaddition reaction between cyclobutane 4 and PhCHO.

\begin{tabular}{|c|c|c|c|c|}
\hline Solvent & $\begin{array}{c}\text { Catalyst } \\
(\mathbf{1 0 ~ m o l \% )}\end{array}$ & $\begin{array}{c}\text { Yield 5 } \\
(\mathbf{\%})\end{array}$ & $\begin{array}{c}\text { Yield 6 } \\
(\mathbf{\%})\end{array}$ & $\begin{array}{c}\text { Yield 7 } \\
(\mathbf{\%})\end{array}$ \\
\hline Toluene & $\mathrm{Sc}(\mathrm{OTf})_{3}$ & 17 & 10 & 0 \\
\hline DMSO & $\mathrm{Sc}(\mathrm{OTf})_{3}$ & 0 & 0 & 0 \\
\hline DMF & $\mathrm{Sc}(\mathrm{OTf})_{3}$ & 0 & 0 & 0 \\
\hline THF & $\mathrm{Sc}(\mathrm{OTf})_{3}$ & 0 & 0 & 0 \\
\hline DCE & $\mathrm{Sc}(\mathrm{OTf})_{3}$ & 0 & 17 & 0 \\
\hline DCM & $\mathrm{ZnBr}_{2}$ & 2 & 2 & 0 \\
\hline DCM & $\mathrm{FeCl}_{3}$ & 25 & 10 & 0 \\
\hline
\end{tabular}

Reagents and conditions: PhCHO (5.0 equiv.), $40{ }^{\circ} \mathrm{C}, 8 \mathrm{~h}$.

With the encouraging result of successful tetrahydropyran formation, we repeated the [4+2]-cycloaddition reaction with a limited range of aromatic and unsaturated aldehydes using the optimized conditions (Scheme 5, Table 3).

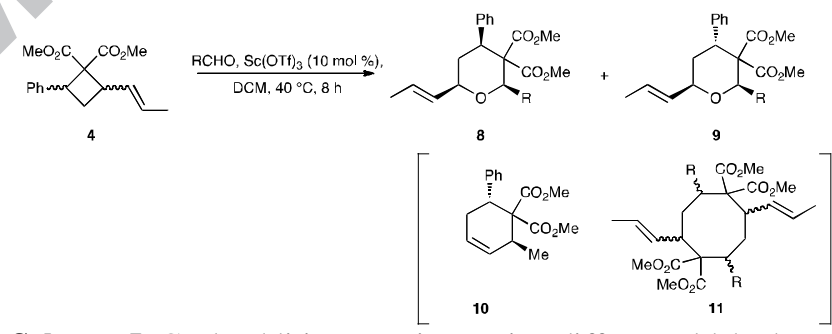

Scheme 5. Cycloaddition reactions using different aldehydes.

Table 3. Yields for the cycloaddition reactions using different aldehydes.

\begin{tabular}{|l|c|c|c|c|}
\hline \multicolumn{1}{|c|}{ RCHO (equiv.) } & $\mathbf{8 ( \% )}$ & $\mathbf{9 ( \% )}$ & $\mathbf{1 0}(\boldsymbol{\%})$ & $\mathbf{1 1}(\boldsymbol{\%})$ \\
\hline $4-\mathrm{MeOC}_{6} \mathrm{H}_{4} \mathrm{CHO}(1.0)$ & Traces & 0 & 0 & 0 \\
\hline $4-\mathrm{NO}_{2} \mathrm{C}_{6} \mathrm{H}_{4} \mathrm{CHO}(1.2)$ & 0 & 0 & 33 & 0 \\
\hline $\mathrm{Ph}-\mathrm{CH}=\mathrm{CH}-\mathrm{CHO}(1.2)$ & 27 & 9 & 10 & 3 \\
\hline $\mathrm{CH}_{2}=\mathrm{CH}-\mathrm{CHO}(3.0)$ & 12 & 8 & 15 & 2 \\
\hline
\end{tabular}

Introducing either electron-donating or electron-withdrawing groups to the aromatic ring had detrimental effects on the reaction, shutting down formation of the desired tetrahydropyran product; the major product being the rearrangement to give cyclohexene 10 (Table 3). More investigation is needed to account for this unusual observation. However, the unsaturated aldehydes acrolein and cinnamaldehyde did produce the desired tetrahydropyran products $\mathbf{8}$ and $\mathbf{9}$. Unlike benzaldehyde, these tetrahydropyran products lack a high diastereomeric excess and structural analysis showed them to be epimeric at the 4-position. This may suggest a change in the reaction mechanism; the stereochemical outcome of the reaction may be related to the stereochemistry of the starting cyclobutane, further studies are underway regarding the reaction mechanism. Significant amounts of rearranged cyclohexene by-product $\mathbf{1 0}$ and trace amounts of 
dimer 11 were also present, but no adducts were observed from the bond cleavage leading to the benzylic cation.

\section{Conclusion}

We have successfully carried out a unique investigation comparing an aromatic ring and an allyl group as donors in the donor-acceptor cyclobutane [4+2]-cycloaddition reaction. The crucial fact that cyclobutane ring cleavage exclusively led to the allylic cation with no sign of the alternate bond cleavage demonstrated, at least for this system, allylic stablisation is superior to benzylic stablisation for this [4+2]-cycloaddition. We have shown that when the donor-acceptor cyclobutane has a choice of cleavage between a benzylic bond and an allylic bond, only the allylic bond is broken under Lewis acid conditions. We are currently looking at making use of this knowledge in expanding the reaction and the synthesis of highly substituted tetrahydropyrans.

\section{References}

1. S. D. R. Christie, R. J. Davoile, M. R. J. Elsegood, R. Fryatt, R. C. F. Jones and G. J. Pritchard, Chem. Commun., 2004, 2474; S. D. R. Christie, R. J. Davoile and R. C. F. Jones, Org. Bio. Chem., 2006, 4, 2683; S. D. R. Christie, J. Cummins, M. R. J. Elsegood and G. Dawson, Synlett, 2009, 257.

2. E. A. Ellart, M. R. J. Elsegood, S. D. R. Christie and G. J. Pritchard, Chem. Commun., 2009, 7339.

3. W. R. Bowman, J. E. Lyon and G. J. Pritchard, Synlett, 2008, 2169; W. R. Bowman, J. E. Lyon and G. J. Pritchard, ARKIVOC, 2012, part vii, 210. S. D. R. Christie, A. D. Warrington, C. J. Lunniss, Synthesis, 2009, 148. R. J. Davoile, D. T. Rutherford, S. D. R. Christie, Tetrahedron Lett., 2000, 41, 1255.

4. For example see:- N. R. Irlapati, J. E. Baldwin, R. M. Adlington, G. J. Pritchard and A. R. Cowley, Tetrahedron, 2006, 62, 4603; R. M. Adlington, J. E. Baldwin, A. V. W. Mayweg and G. J. Pritchard, Org. Lett., 2002, 4, 3009; R. M. Adlington, J. E. Baldwin, G. J. Pritchard, A. J. Williams and D. J. Watkin, Org. Lett., 1999, 1, 1937; N. R. Irlapati, J. E. Baldwin, R. M. Adlington and G. J. Pritchard, Org. Lett., 2003, 5, 2351; J. E. Baldwin, R. M. Adlington, A. Conte, N. R. Irlapati, R. Marquez and G. J. Pritchard, Org. Lett., 2002, 4, 2125.

5. For examples see:- M. F. A. Adamo, R. M. Adlington, J. E. Baldwin, G. J. Pritchard and R. E. Rathmell, Tetrahedron, 2003, 59, 2197; J. E. Baldwin, A. M. Fryer and G. J. Pritchard, Bioorg. Med. Chem. Lett., 2000, 10, 309; R. M. Adlington, J. E. Baldwin, D. Catterick and G. J. Pritchard, Chem. Commun., 1997, 1757.

6. A. Ahmed, S. D. R. Christie, M. R. J. Elsegood and G. J. Pritchard, Chem. Commun., 2013, 49, 7489.

7. S. Shimada, K. Saigo, H. Nakamura, M. Hasegawa, Chem. Lett., 1991, 20, 1149.

8. A. T Parsons and J. S. Johnson, J. Am. Chem. Soc., 2009, 131, 14202 .

9. M. M. A. R. Moustafa and B. L. Pagenkopf, Org. Lett., 2010, 12, 4732; M. M. A. R. Moustafa, A. C. Stevens, B. P. Machin and B. L. Pagenkopf, Org. Lett., 2010, 12, 4736; A. C. Stevens, C. Palmer and B. L. Pagenkopf, Org. Lett., 2011, 13, 1528; B. P. Machin and B. L. Pagenkopf, Synlett, 2011, 2799; R. Okado, A. Nowaki, J. Matsuo, H. Ishibashi, Chem. Pharm. Bull., 2012, 60, 21.

10. J. Matsuo, S. Sasaki, H. Tanaka and H. Ishibashi, J. Am. Chem. Soc., 2008, 130, 11600; J. Matsuo, S. Sasaki, T. Hoshikawa and H. Ishibashi, Tetrahedron Lett., 2009, 50, 5831; J. Matsuo, S. Sasaki, T. hoshikawa and H Ishibashi, Org. Lett., 2009, 11, 3822; J. Matsuo, S. Negishi, H. Ishibashi, J. Matsuo, R. Okado and H. Ishibashi, M. Kawano, Org. Lett., 2010, 12, 3266; S. Negishi, H. Ishibashi and J. Matsuo, Org. Lett., 2010, 12, 4984; T. Kiuchi, J. Matsuo and H. Ishibashi, Tetrahedron Lett., 2012, 53, 432; M. Kawano, T. Kiuchi, S. Negishi, H. Tanaka, T. Hoshikawa, J. Matsuo and H. Ishibashi, Anrew. Chem. Int. Ed., 2013, 52, 906

11. G. Shan, X. Sun Q. Xia and Y. Rao, Org. Lett., 2011, 13, 5770; Y. Cheng, X. Han. H Ouyang and Y. Rap, Chem. Commun., 2012, $48,1757$.

12. R. K. Boeckman Jr., M. R. Reeder, J. Org. Chem., 1997, 62, 6456.

13. A. Ma, S Zhu and D. Ma, Tetrahedron Lett., 2008, 49, 3075. 
A Comparison of the Benzylic and the Allylic Group as a Donor in the Formal [4+2] Cycloaddition to Tetrahydropyrans using Donor-Acceptor Cyclobutanes

\section{Highlights:-}

A formal [4+2]-cycloaddition reaction of donoracceptor cyclobutanes gives tetrahydropyrans.

The allyl group was shown to be a better donor than benzyl.

A number of highly substituted tetrahydropyrans were prepared. 


\section{Graphical Abstract}

To create your abstract, type over the instructions in the template box below.

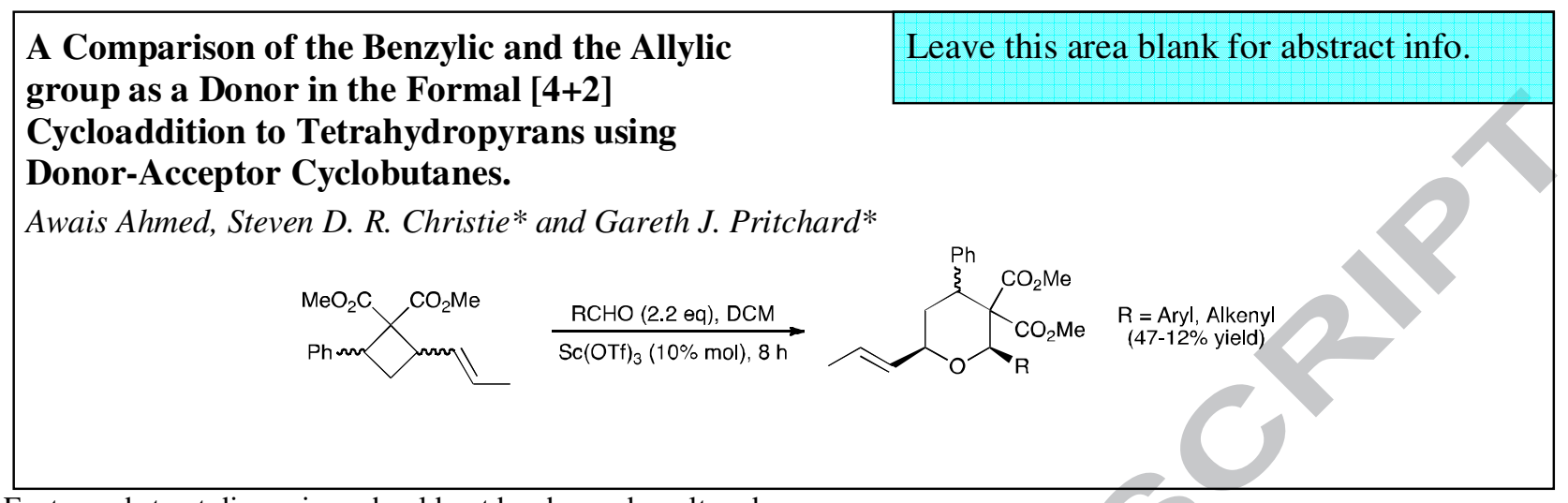

Fonts or abstract dimensions should not be changed or altered. 